\title{
THE CLINICAL EVALUATION OF AUREOMYCIN 1,2,3
}

\author{
By HENRY BRAINERD, EDWIN H. LENNETTE, GORDON MEIKLEJOHN, \\ HENRY B. BRUYN, JR., AND WILLIAM H. CLARK
}

\author{
(From the Infectious Disease Laboratory ${ }^{4}$ of the San Francisco Hospital and the State of \\ California Virus and Rickettsial Disease Laboratory, Berkeley, California)
}

Aureomycin (1), an antibiotic agent derived from Streptomyces aureofaciens, has been demonstrated to have therapeutic activity against a wide variety of bacterial, rickettsial, and viral pathogens. In vitro and in vivo activity has been observed against most gram-positive cocci, and gram-negative cocci and rods (1-6). In addition, in vivo activity, has been shown against the rickettsiae of the typhus, Rocky Mountain spotted fever, scrub typhus, and $Q$ fever groups, as well as against the viruses of lymphopathia venereum and psittacosis $(7,8)$. Animal toxicity has been noted to be very slight (9).

Successful clinical trials have been reported in a wide variety of bacterial and rickettsial infections, as well as infections due to lymphopathia venereum virus and the causative agent of primary atypical pneumonia (4, 6, 10-24). Toxic reactions have been few and insignificant. Since the number of patients reported with each type of infection has been small, and since all patients were treated by the oral or intramuscular routes, we are documenting the results of clinical trial of aureomycin in 116 patients observed since May, 1948. Many of these patients received aureomycin by the intravenous route. Assays of serum concentrations of aureomycin were carried out in most patients by means of a method previously described (25). In vitro sensitivity tests on the infecting organisms were carried out wherever pos-

\footnotetext{
1 Presented at the Second National Symposium on Recent Advances in Antibiotics Research held in Washington, D. C., April 11-12, 1949, under the auspices of the Antibiotics Study Section, National Institutes of Health, Public Health Service, Federal Security Agency.

2 Aided by grants from C. S. Howard Donation and the Fleischner Endowment Fund.

3 The aureomycin used in this investigation was provided by Lederle Laboratories, Division of the American Cyanamid Company.

${ }^{4}$ This laboratory is supported by the Divisions of Medicine and Pediatrics of the University of California Medical School and by the Department of Public Health of the City and County of San Francisco, California.
}

sible. Studies on the clinical pharmacology of aureomycin are being presented elsewhere (26).

\section{MATERIALS AND METHODS}

The majority of the patients represented in the present report were treated with aureomycin while hospitalized at the San Francisco Hospital or the University of California Hospital. In several instances, the patients were treated in other locations under the guidance of one or more of the present investigators, and laboratory studies were carried out under their direction. Most of the viral and rickettsial isolations and serological procedures were carried out at the State of California Virus and Rickettsial Disease Laboratory. The assays of serum aureomycin concentration were carried out at the Infectious Disease Laboratory, as were determinations of the aureomycin sensitivity of the infecting bacterial organisms (Tables Ia and Ib).

All patients were accepted for inclusion in the investigative series only when adequate clinical and laboratory criteria for diagnosis were satisfied.

\section{Dosage and Route of Administration}

Adult patients in this series taking aureomycin by mouth generally received 1 gram every four to eight hours. Most patients received 1 gram every six hours. In many infections this dosage schedule may prove to be excessive. Several patients suffering from primary atypical pneumonia have responded satisfactorily to 0.5 gram every six hours, and 0.5 gram every eight hours seemed adequate in one patient whose urinary tract infection was due to a moderately susceptible organism. On the other hand, large doses may be required to produce satisfactory results in patients infected with resistant bacteria such as Pseudomonas aeruginosa and Proteus vulgaris, in typhoid fever, and in $Q$ fever.

Sixty-eight ${ }^{5}$ individuals received 337 intravenous injections of aureomycin. In 327 instances the aureomycin was dissolved immediately before injection in a solution containing $131 \mathrm{mg}$. of $l$-leucine per $5 \mathrm{cc}$. A concentration of $10 \mathrm{mg}$. of aureomycin per cc. was used. A 0.784 per cent sodium carbonate solution appeared to be a satisfactory diluent in 10 intravenous injections. As many as 36 injections of $100 \mathrm{mg}$. were given in an individual patient without untoward result. The individual intravenous dose varied from 40 to $200 \mathrm{mg}$. Intravenous doses of 50 to $100 \mathrm{mg}$. have been demonstrated to produce serum levels of from 2.5 to $10 \mu \mathrm{g}$. five minutes after

5 This figure includes 12 normal individuals who received intravenous aureomycin in the course of pharmacological experiments. 
injection $(25,26)$. Concentrations of aureomycin in excess of $0.15 \mu \mathrm{g}$. per cc. usually persisted from six to eight hours. Combined simultaneous oral and intravenous treatment resulted in serum concentrations as high as 20 to $80 \mu \mathrm{g}$. per cc.

Intravenous medication was used according to two general plans:

1) One or two intravenous doses were given initially, often combined with oral doses, to achieve an immediate high blood concentration of aureomycin. High serum levels of aureomycin often did not appear for one or more days when only oral administration was used. These initial priming doses were followed by maintenance on oral therapy (32 patients).

2) Three intravenous doses, usually of $100 \mathrm{mg}$., were administered at six-hour intervals during the day supplemented by one oral dose at night during the entire course of treatment (22 patients). Two patients were treated satisfactorily with three intravenous injections daily without supplementary oral medication.

The therapeutic effects of intravenous medication did not appear to differ from those following from oral administration alone in infection due to susceptible agents. Treatment by the intramuscular route was abandoned following the very frequent occurrence of painful local reactions and the demonstration that measurable serum concentrations of aureomycin rarely resulted.

While the relationship of in vitro sensitivity tests of infecting organisms and optimum serum aureomycin concentrations to produce favorable clinical response is as yet unknown, such in vitro tests in this laboratory partially helped clarify in which types of infection success or failure would be likely to occur.

In this laboratory most strains of gram-positive cocci and $C$. diphtheriae were sensitive to less than $0.1 \mu \mathrm{g}$. per cc., according to the method used. Most strains of $E$. coli, $A$. aerogenes, $E$. typhosa, Salmonellae, $N$. meningitis, $K$. pneumoniae, $H$. influenzae, and Shigellae were sensitive to less than $1.0 \mu \mathrm{g}$. per cc. Pr. vulgaris and Ps. aeruginosa were found to be susceptible only to from 3.5 to $288 \mu \mathrm{g}$. per cc. (26). Spontaneous development of aureomycin resistance following unsuccessful treatment was observed in only one instance, that of a urinary tract infection due to $E$. coli. In this patient the infecting organism was sensitive to $0.21 \mu \mathrm{g}$. per cc. before the beginning of treatment, while an $E$. coli recovered during relapse was inhibited only by $285 \mu \mathrm{g}$. per cc.

\section{Toxicity}

No serious toxic effects of aureomycin were noted. Nausea and/or vomiting occurred in more than one-half of patients receiving oral doses of 1 gram every four or six hours. Occasionally this was sufficiently severe to prevent further treatment by this route. That this distressing symptom was principally local in cause was evidenced by the fact that only two of 68 patients receiving aureomycin intravenously experienced nausea and in neither instance was the symptom certainly attributable to medication. Patients receiving three intravenous and one oral dose per day did not experience significant nausea. On several occasions positive guaiac reactions for occult blood were observed in the stools of patients receiving aureomycin by mouth. Nausea occasionally subsided spontaneously in spite of continuation of oral therapy. Aluminum hydroxide gels at times appeared to give relief, as did sedative and antispasmodic medications. Frequent or loose stools were commonly observed but did not prevent continuation of therapy. The serum concentration of aureomycin bore no relationship to untoward gastrointestinal manifestations.

Maculo-papular, urticarial, or scarlatiniform rashes were observed in six patients. In two of these the rash could have logically been ascribed to some other cause than aureomycin medication. Drug fever was considered a possibility in two instances. Vertigo occurred in two patients receiving aureomycin intravenously after only short periods of treatment and in the absence of unusually high blood concentrations. The significance of this observation is uncertain. "Black tongue" occurred in two patients. Two instances of glossitis in association with rashes were noted. Local spasm of veins during injection was observed very rarely. No sloughs resulted from extravasation outside the vein. Erythema and pruritus of the perineal area occurred in four patients. Intramuscular injection of aureomycin dissolved in Sorenson's phosphate buffer ( $\mathrm{pH} 7.4)$ and combined with 2 per cent procaine almost invariably resulted in severe, painful, local reactions.

\section{RESULTS}

\section{Typhoid, Salmonella and Shigella Infections}

In this group of patients, the results following aureomycin therapy were variable, and for the most part could not be interpreted as showing a therapeutic effect of the drug. However, in certain cases the results were such as to convince one that the drug had been of specific clinical value.

In one of two carriers of E. typhosa who had no clinical disease, there was temporary absence of the organism during aureomycin therapy. The second carrier showed no change in the stool culture for E. typhosa. In a third patient who developed a biliary fistula following cholecystectomy and who showed the presence of E. typhosa in both feces and in the discharge from the fistula, there was healing of the fistula and abolition of the fecal carrier state following aureomycin therapy. Longterm follow-up of this case has not been completed at this time.

In nine cases of acute typhoid fever, only two showed a response to aureomycin therapy. The first of these patients, L. W., whose course is summarized in Figure 1 and given in detail below, was a 21-month-old child who was started on aureo- 


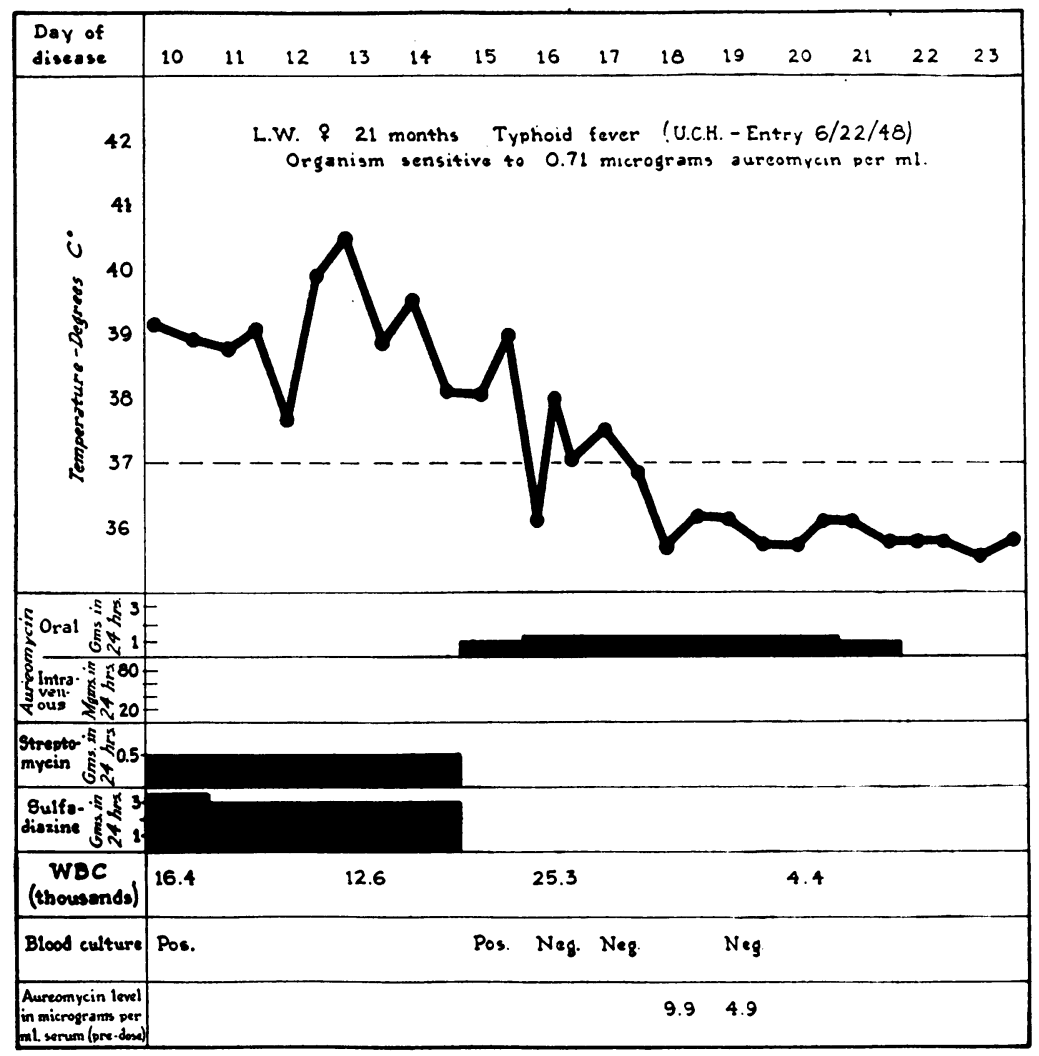

FIG. 1

mycin on the 16th day of fever at which time the blood culture was positive for E. typhosa. She was given 1.0 gram of the drug daily and her temperature was within normal range in 48 hours. Her blood culture became sterile the day after therapy was started.

Case 1. L. W., white, female, age 21 months. This infant entered the University of California Hospital on June 22, 1948. On June 14 she had developed chills, fever and prostration which had continued unabated until hospital admission. A blood culture taken before entry proved to be positive for E. typhosa.

Physical examination revealed the rectal temperature to be $39.4^{\circ} \mathrm{C}$. The child appeared severely ill and was irritable and uncooperative. No other positive physical findings were noted.

Urinalysis was negative. Complete blood count showed: Hemoglobin 11.0 grams per cent; red blood cells 4,100,000 per cubic mm.; white blood cells 16,000 per cubic $\mathrm{mm}$.; neutrophiles 74 per cent; lymphocytes 20 per cent; monocytes 6 per cent. Blood cultures taken on June 24 and June 27 were positive for E. typhosa. Stool cultures on July 2 and July 7 were negative. Urine culture on June 22 revealed only contaminating $E$. coli.

No clinical or bacteriological response followed administration of streptomycin and sulfadiazine from June 23 to June 27. On June 27 aureomycin therapy was begun. The patient received 0.16 gram by mouth every four hours until July 3 . The temperature became normal in 48 hours and simultaneous general improvement was noted. Blood culture 24 hours after the institution of aureomycin was negative and the blood stream remained sterile thereafter. On July 2 and 3 an urticarial rash appeared over the trunk and faded spontaneously. The child had previously had urticaria after ingestion of several different foods. The possibility of aureomycin sensitivity remained uncertain. Further convalescence was uneventful.

The other patient showing a favorable response was also a child, age 22 months, who was started on 1.0 gram per day in four daily doses on the 13th day of disease at which time the blood culture was positive for E. typhosa and the temperature was $104^{\circ} \mathrm{F}$. Her temperature dropped to below $100^{\circ} \mathrm{F}$. within 48 hours and was within normal range within four days. There was marked symptomatic improvement within 48 hours.

Another patient was treated for a short time with aureomycin and then chloromycetin therapy was instituted. During aureomycin therapy the 
TABLE I-A

Summary of the results of aureomycin treatment in bacterial infections

\begin{tabular}{|c|c|c|c|c|}
\hline \multirow{2}{*}{ Disease } & \multirow{2}{*}{$\begin{array}{l}\text { Total } \\
\text { no. of } \\
\text { cases }\end{array}$} & \multicolumn{3}{|c|}{ Results } \\
\hline & & Good & Equivocal & Poor \\
\hline Urinary tract infections & 13 & $10^{*}$ & 1 & 2 \\
\hline Brucellosis & 3 & 2 & - & 1 \\
\hline Chancroid & 4 & 4 & - & - \\
\hline Typhoid fever & 9 & 2 & 3 & 4 \\
\hline Typhoid carrier & 3 & - & 1 & 2 \\
\hline Salmonellosis & 4 & 1 & 3 & - \\
\hline Shigellosis & 2 & 2 & - & - \\
\hline Leptospirosis & 1 & 1 & - & - \\
\hline Pneumonia, pneumococcal & 2 & 1 & 1 & - \\
\hline Pneumonia, staphylococcal & 1 & - & 1 & - \\
\hline Septicemia, pseudomonas & 1 & - & 一 & 1 \\
\hline Erysipelas & 1 & 1 & 一 & - \\
\hline $\begin{array}{l}\text { Subacute bacterial endocar- } \\
\text { ditis, Streptococcus } \\
\text { fecalis }\end{array}$ & 2 & - & 2 & - \\
\hline Peritonitis, generalized & 2 & 2 & - & $\longrightarrow$ \\
\hline Pelvic abscess $-E$. coli & 1 & - & 1 & 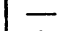 \\
\hline Post-operative fecal fistula & 1 & - & - & 1 \\
\hline Pyoderma-staphylococcal & 1 & 1 & - & - \\
\hline
\end{tabular}

* Five patients had recurrences or reinfection.

blood culture became negative but the temperature course was unchanged. Two days after chloromycetin was started the temperature had dropped to within normal range and remained there. This case is summarized in Figure 2 and given in detail as follows :

Case 2. N. S., white female, age 43 ( $\mathrm{SFH} 74120$ ). Two weeks before admission to the San Francisco Hospital on March 9, 1949, this patient had noted the sudden onset of fever following the extraction of an abscessed tooth. She was admitted to another hospital where she had had slight diarrhea. Her blood culture was found to be positive for E. typhosa and her Widal test was

TABLE I-B

Summary of the results of aureomycin treatment in rickettsial, viral and miscellaneous infections

\begin{tabular}{|c|c|c|c|c|}
\hline \multirow{2}{*}{ Disease } & \multirow{2}{*}{$\begin{array}{l}\text { Total } \\
\text { no. of } \\
\text { cases }\end{array}$} & \multicolumn{3}{|c|}{ Results } \\
\hline & & Good & Equivocal & Poor \\
\hline $\begin{array}{l}Q \text { fever } \\
\text { Primary atypical pneumonia } \\
\text { Psittacosis } \\
\text { Herpes zoster } \\
\text { Varicella } \\
\text { Lymphopathia venereum } \\
\text { Infectious mononucleosis } \\
\text { Pneumonia-undetermined } \\
\text { etiology } \\
\text { Pemphigus } \\
\text { Primary coccidioidal } \\
\text { pneumonia }\end{array}$ & $\begin{array}{r}29 \\
16 \\
3 \\
1 \\
2 \\
1 \\
3 \\
6 \\
3 \\
1\end{array}$ & $\begin{array}{r}18 \\
13 \\
3 \\
1 \\
\frac{1}{2} \\
- \\
-\end{array}$ & $\begin{array}{l}4 \\
\frac{3}{-1} \\
\frac{1}{3} \\
2 \\
2 \\
\end{array}$ & $\begin{array}{l}\frac{7}{-} \\
\frac{1}{-} \\
\frac{1}{1} \\
1\end{array}$ \\
\hline
\end{tabular}

positive in a dilution of $1: 320$. She was then transferred to the San Francisco Hospital.

Past history was irrelevant. Examination at the time of admission revealed the temperature to be $40^{\circ} \mathrm{C}$., pulse 100 per minute, respiration 24 per minute. The patient appeared toxic and lethargic, but was readily aroused. Numerous fresh rose spots were present on the abdomen. The spleen was not palpable. Physical examination was otherwise negative.

Urinalysis revealed one-plus albuminuria. Complete blood count showed: red blood cells 4,200,000 per cubic mm.; packed cell volume 34 per cent; white blood cells 3,800 per cubic mm.; neutrophiles 66 per cent; eosinophiles 2 per cent; lymphocytes 32 per cent. Blood culture was positive for E. typhosa. Urine and stool cultures were repeatedly negative for pathogens. Agglutinations with typhoid $\mathrm{H}$ and $\mathrm{O}$ antigens were both positive in a titer of 1:160. Chest X-ray was negative.

On March 11 the patient was started on aureomycin. She received $100 \mathrm{mg}$. intravenously every six hours. One oral dose of 1 gram was substituted for the night intravenous dose. Aureomycin was continued until March 14. Although the blood culture had become negative by March 12, no effect on the temperature or condition of the patient was apparent. On March 14 the patient was begun on chloromycetin. She received 1 gram every six hours by mouth until March 16 when the dose was changed to 0.5 gram every three hours by mouth. By March 17 the temperature had become normal and the patient appeared improved. She remained afebrile thereafter. Chloromycetin was discontinued on March 21.

In four of the remaining patients with acute typhoid fever, aureomycin therapy seemed to have caused a slight effect on the fever curve which could be interpreted as a temporary suppression of the infecting organism. In these patients the therapy caused no change in the course of the disease.

In four cases of infection due to organisms of the Salmonella group, unequivocally good results were obtained in only one, that of a septicemia without enteritis due to Salmonella schottmulleri. In this case, that of a 15-month-old male, penicillin, streptomycin, and sulfadiazine had had no effect on the blood culture which became negative 48 hours after starting aureomycin. The temperature came to within normal range after a similar interval. The possibility that this apparent response to the drug represents a spontaneous recovery is admitted but the rapidity of the temperature response led us to conclude that it was probably a therapeutic effect.

In three cases of enteritis due to $S$. enteriditis, $S$. typhimurium and $S$. schottmulleri equivocal re- 


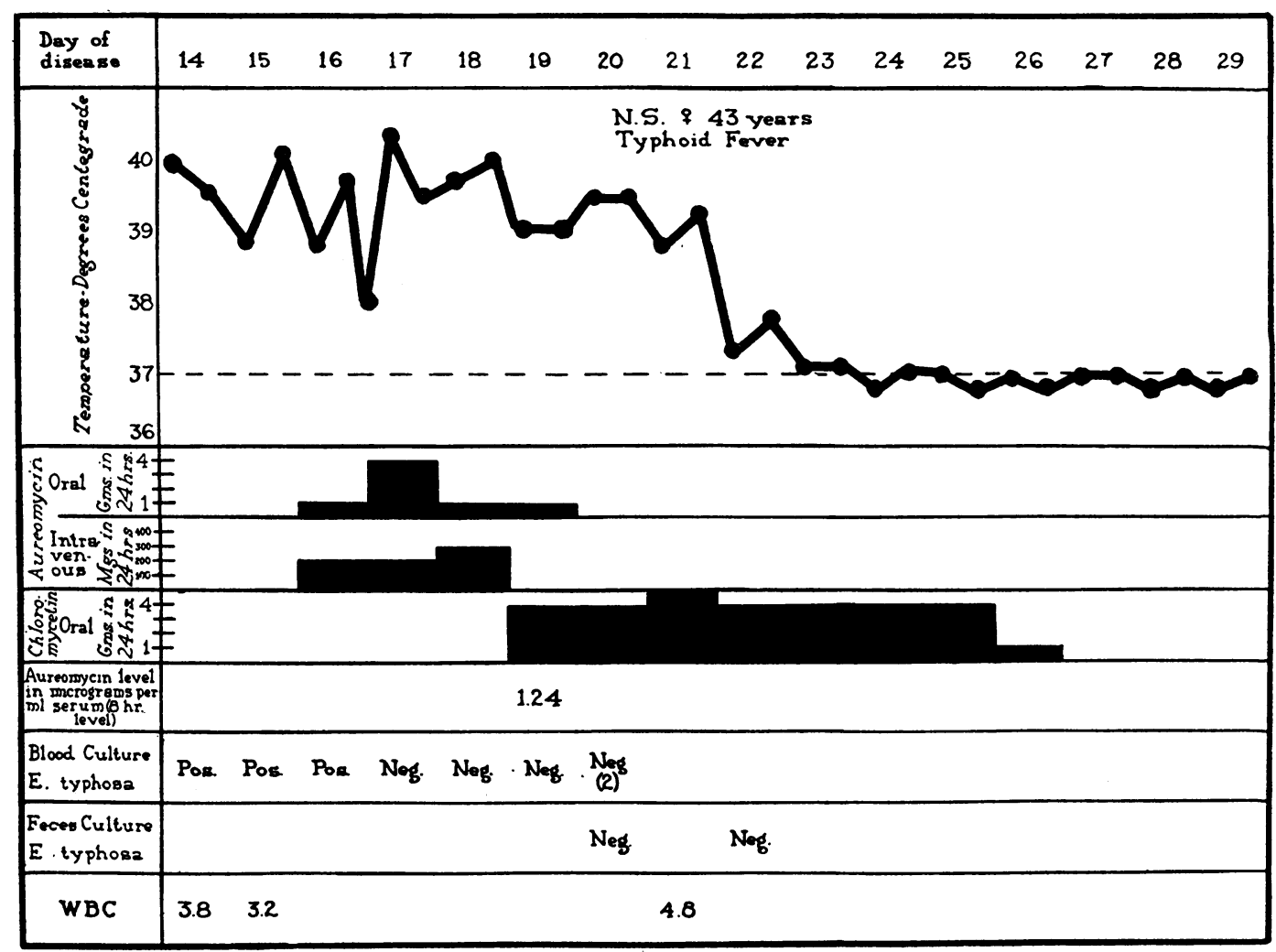

FIG. 2

sults were noted. S. enteriditis and $S$. schottmulleri were not found in the stool cultures during treatment but promptly reappeared when therapy was stopped. In the case of $S$. typhimurium, the organism was not found in the stool after starting aureomycin and there was no recurrence.

Two cases of Shigella infections have been treated, both with apparently good immediate results. A four-year-old girl with dysentery due to Shigella showed prompt bacteriological and clinical response with no recurrence following cessation of therapy. In the second case, a four-year-old boy with dysentery due to Shigella flexner, the stool cultures were free of this organism 24 hours after

TABLE II

The effect of aureomycin on infections of the urinary tract

\begin{tabular}{|c|c|c|c|}
\hline Patient & Infecting organisms & Anatomical lesions & Result \\
\hline $\begin{array}{l}\text { L. A. } \\
\text { R. I. } \\
\text { T. Y. } \\
\text { S. U. } \\
\text { B. A. }\end{array}$ & $\begin{array}{l}\text { A. aerogenes } \\
\text { Strep. fecalis, E. Coli, P. vulgaris } \\
\text { Staph. aureus, Strep. fecalis } \\
P . \text { vulgaris } \\
\text { Ps. aeruginosa, Staph. aureus }\end{array}$ & $\begin{array}{l}\text { None } \\
\text { None } \\
\text { None } \\
\text { Pyelectasis } \\
\text { Ureteroplasty }\end{array}$ & $\begin{array}{l}\text { Rapid sterilization } \\
\text { Rapid sterilization } \\
\text { Rapid sterilization } \\
\text { Rapid sterilization } \\
\text { Sterilization; later recurrence of both organ- } \\
\text { isms }\end{array}$ \\
\hline & Ps. aeruginosa, $A$. aerogenes & $\begin{array}{l}\text { Possible vesico-vaginal } \\
\text { fistula }\end{array}$ & Sterilization; later recurrence of pseudomonas \\
\hline $\begin{array}{l}\text { R. E. } \\
\text { F. E. } \\
\text { Y. O. } \\
\text { C. O. } \\
\text { B. R. } \\
\text { C. A. } \\
\text { F. C. } \\
\text { G. F. }\end{array}$ & $\begin{array}{l}\text { Ps. aeruginosa } \\
\text { Ps. aeruginosa, Strep. fecalis } \\
\text { Ps. aeruginosa } \\
\text { E. coli } \\
\text { Ps. aeruginosa } \\
\text { Ps. aeruginosa } \\
\text { Ps. aeruginosa } \\
\text { Ps. aeruginosa }\end{array}$ & $\begin{array}{l}\text { Ureteroplasty } \\
\text { Urethral valve } \\
\text { Hydronephrosis } \\
\text { Hydronephrosis } \\
\text { Hydronephrosis } \\
\text { Hydronephrosis and calculi } \\
\text { Hydronephrosis } \\
\text { Cord bladder }\end{array}$ & $\begin{array}{l}\text { Sterilization; later recurrence } \\
\text { Sterilization; la ter reinfection with } E \text {. coli } \\
\text { Sterilization; no follow-up } \\
\text { Sterilization; recurrence with resistant variant } \\
\text { Sterilization; no follow-up } \\
\text { Suppression and disappearance of fever } \\
\text { No effect; received only } 1.5 \text { grams orally } \\
\text { No effect; received only } 100 \mathrm{mg} \text {. in travenously }\end{array}$ \\
\hline
\end{tabular}


starting aureomycin but the diarrhea continued for three more days. Long term bacteriological follow-up of this second case has not been completed.

While the total number of cases of infection due to organisms of the Typhoid-Salmonella-Shigella group is not large, it is probably a safe conclusion that, in our hands, aureomycin has been of doubtful value in most cases.

\section{Infections of the Urinary Tract (Table II)}

Aureomycin has been reported as favorably affecting infections of the urinary tract by others $(14,17,24)$. Fourteen individuals with urinary tract infections, in all instances previously treated unsuccessfully with sulfonamides and other antimicrobial agents, were selected for therapy with aureomycin. In 11 of these patients chronic infection was certainly or probably associated with obstruction of the urinary passages. Three patients suffered from acute non-obstructive infections. All of the latter group responded quickly by sterilization of the urine and disappearance of symptoms. While temporary sterilization of the urine was accomplished in 10 patients in the former group, excepting two who received very small amounts of aureomycin, relapse or reinfection occurred in all patients in whom follow-up cultures were obtainable. In only one instance was decrease in the sensitivity of the organism to aureomycin isolated during relapse observed. It was felt that aureomycin controlled the infection in the instances of hydronephrosis of pregnancy so that the fetus could be carried to term. In one instance pyelolithotomy was successfully accomplished during a period of suppression of infection by aureomycin. Infections due to Pseudomonas aeruginosa proved to be the most difficult to treat successfully.

\section{Brucellosis}

Three cases of brucellosis have been treated with aureomycin in the present investigation. Spink (18) has reported on 24 cases of brucellosis treated with aureomycin with favorable results.

The first case in the present report was that of a 21-year-old female who was treated for a period of 23 days starting on about the 63rd day of the

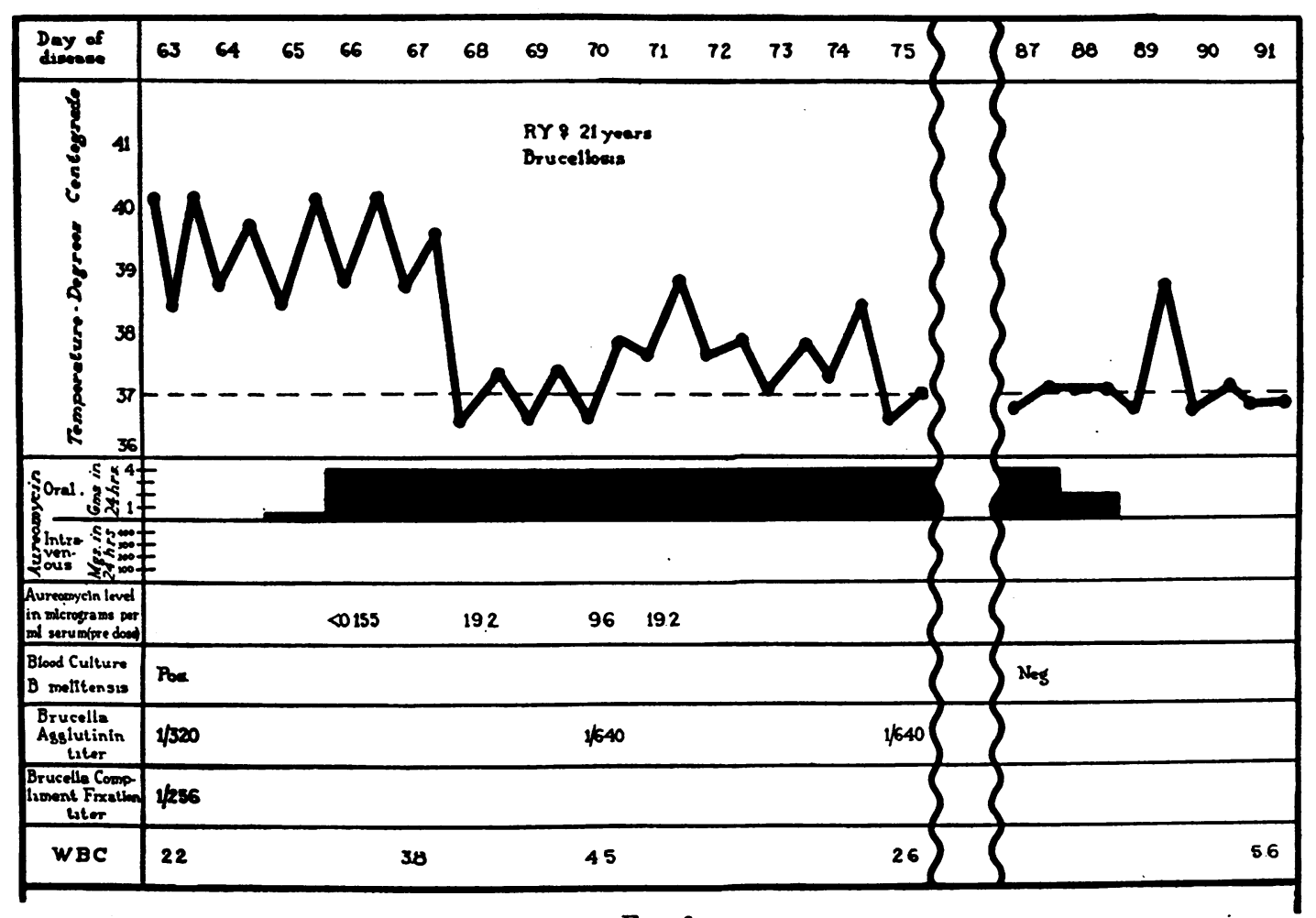

FIG. 3 
disease. Her response was very satisfactory and the course is summarized in Figure 3 and a detailed case history follows.

Case 3. R. Y., white, female, age 21 (SFH 39899). The patient entered San Francisco Hospital on December 16,1948 , stating that she had had progressively severe bouts of nocturnal fever and sweating accompanied by joint pains for six weeks. In addition she had developed frequent nausea and vomiting and occasional epigastric pain during these episodes. Six weeks previous to the onset of her illness she had returned from several months' stay in Mexico. Her past history was irrelevant.

On examination the temperature was found to be $38.4^{\circ} \mathrm{C}$., pulse 120 per minute, respiration 21 per minute. The patient appeared severely and chronically ill. There was slight generalized lymphadenopathy. The liver edge was palpated $3 \mathrm{~cm}$. below the right costal margin. The spleen extended $7 \mathrm{~cm}$. below the left costal margin. Physical examination was otherwise essentially negative.

Urinalysis revealed minimal albuminuria. Complete blood count showed: Hemoglobin 10 grams per cent; red blood cells 3,410,000 per cubic mm.; white blood cells 1,450 per cubic mm.; neutrophiles 64 per cent; 1ymphocytes 38 per cent. Corrected sedimentation rate (Wintrobe) was $17 \mathrm{~mm}$. per hour. Stool was negative for occult blood and pathogens. Chest X-ray, tuberculin and coccidioidin skin tests were negative. Agglutinations for typhoid and paratyphoid were repeatedly negative. Complement fixations for $Q$ fever and psittacosis were negative. Brucella agglutinins were present in a titer of $1: 320$ on December 23, 1948 and gradually rose to $1: 1,280$ on January 10,1949 . After repeatedly sterile blood cultures, Brucella melitensis (type H2s) was isolated on January 3, 1949. On January 5 the patient received $50 \mathrm{mg}$. of aureomycin orally every six hours. On the following day this was increased to $250 \mathrm{mg}$. The patient received 1 gram every six hours from January 7 to January 28 , and then 0.5 gram every six hours until January 30. Rapid defervescence occurred within 48 hours although the patient continued to run a lowgrade fever until January 22. Symptomatic improvement coincided with the febrile response. On January 29 the patient had a chill followed by a transient febrile rise and was noted to have a macular rash over the entire body which faded rapidly by the next day. This patient has since remained entirely well.

The second case of brucellosis was that of a 32year-old man whose treatment was started on the 15 th day of disease and who received 4 grams per day for 13 days. The diagnosis in this case was based on a rise in Brucella agglutinin titer of from $1: 500$ on the sixth day of disease to $1: 2,560$ on the 13th day of the disease. His temperature, which had ranged around $100^{\circ}$ to $103^{\circ} \mathrm{F}$. for 15 days, fell to within normal limits within 48 hours and remained there.
The third individual, a 39-year-old woman who had had chronic brucellosis for four years, received 4 grams per day for 13 days after a preliminary three-day period during which she received 250 , 500 , and $750 \mathrm{mg}$., respectively. Amelioration of subjective symptoms was marked and almost immediate. Her expected bouts of low-grade fever did not occur during treatment or for two weeks afterward. At that time she again developed malaise and occasional low-grade fever. It was considered that aureomycin had probably exerted temporary suppressive effect on the infection.

\section{Leptospirosis}

Heilman (27) reported that aureomycin exhibited greater therapeutic effect on experimental infection with Leptospira icterohemorrhagica than did penicillin. A single severely ill patient was treated with aureomycin administered intravenously and orally from the sixth to 17 th day of illness. Prompt amelioration of the symptoms appeared to result. The blood urea declined from $120 \mathrm{mg}$. per cent to $24 \mathrm{mg}$. per cent within one week. Liver function returned to normal more slowly. Although the rapid improvement could not certainly be attributed to aureomycin, it was felt that specific anti-spirochaetal effect was most likely. This case is presented in detail.

Case 4. J. J., white, male, age 42 (SFH 5389). This patient was brought to the San Francisco Hospital in an unconscious state on January 26, 1949. His wife stated that he had developed fever, chilly sensations, and malaise four days previously. He complained of severe aching in the shoulders, back and knees. He lost his appetite but did not vomit. His skin became yellow and his vision was blurred. On the morning of entry his speech became confused. Shortly thereafter he had three generalized convulsions and lapsed into coma. The patient was a sewer worker and had frequently encountered rats.

On examination his temperature was $37.8^{\circ} \mathrm{C}$., pulse was unobtainable, respiration 22 per minute. He was completely unconscious. The skin and sclerae were icteric. Clotted blood was present in the right naris. The liver dullness extended three finger-breadths below the right costal margin. The spleen was not palpable. The reflexes were slightly more active on the right. During the 24 hours following hospital admission numerous subconjunctival hemorrhages appeared and purpuric spots were noted in the skin. The patient became semiconscious but remained confused.

Urinalysis revealed mild albuminuria and a few hyaline and granular casts. Bile was absent. Hematological studies showed: packed cell volume- 35 per cent; white 
TABLE III

Liver and kidney function in patient with leptospirosis treated with aureomycin

\begin{tabular}{|c|c|c|c|c|c|c|c|c|c|}
\hline Date & Jan. 26 & Jan. 27 & Jan. 28* & Jan. 31 & Feb. 2 & Feb. 3 & Feb. 5 & Feb. 15 & Feb. 25 \\
\hline $\begin{array}{l}\text { Icteric index, units } \\
\text { Blood urea, mg. per cent } \\
\text { Cephalin flocculation }\end{array}$ & $\begin{array}{l}125 \\
+t+\end{array}$ & $\begin{array}{c}135 \\
120 \\
+++\end{array}$ & $\begin{array}{r}150 \\
75 \\
+++\end{array}$ & $\begin{array}{c}163 \\
21 \\
++++\end{array}$ & 132 & $\overline{52}$ & $\begin{array}{l}50 \\
24\end{array}$ & 24 & 17 \\
\hline
\end{tabular}

* Treatment started

blood cells 13,650 per cubic mm.; neutrophiles 87 per cent; lymphocytes 13 per cent. A spinal puncture revealed a xanthochromic fluid containing 6,250 red blood cells per cubic $\mathrm{mm}$. On January 28 Leptospira were demonstrated by darkfield examination of the blood. $\mathrm{Ag}$ glutinins for $L$. canicola were present in a dilution of $1: 100$. No agglutinins for $L$. icterohemorrhagica were present. Darkfield examination of the blood on January 29 was again positive. Agglutinins for both $L$. canicola and $L$. icterohemorrhagica were present in a titer greater than $1: 10,000$ on February 4. Complement fixation reactions for $Q$ fever and psittacosis were negative.

On January 28 the patient was begun on aureomycin therapy. He received 1 gram orally every six hours until February 8. In addition, $100 \mathrm{mg}$. were administered intravenously three times daily during the first five days.

The patient's sensorium cleared rapidly and his appetite and strength returned. The icteric index and blood urea were gradually decreased. The patient had little fever at any time after hospital admission. (See Table III.)

\section{$Q$ Fever}

Twenty-nine patients, proven by serologic or animal tests to have $Q$ fever, have been treated to the present time. A large number of these cases have been presented in a separate report (13). In 19 patients the drug was given orally. Two were treated by intramuscular injections and seven patients were treated by both the oral and intramuscular routes. One individual has been treated by the combined oral and intravenous routes.

The two patients treated by the intramuscular route alone recovered quickly but no conclusions can be drawn. They were treated early in this study and with what is now considered an inadequate dosage.

Fourteen of the 19 patients receiving aureomycin by the oral route alone were treated within seven days of onset of their illness. Treatment in the remaining four patients was begun on the 10th, 13th, 17th, and 23rd days, respectively, after onset of illness. Six patients became afebrile within 48 hours after institution of therapy and seven within
72 hours. Fever persisted in three patients for five days, however, in one for eight days, and in one for 13 days after beginning of treatment. The remaining individual had suffered an attack of $Q$ fever two months previously and had continued to run a low-grade fever. Because of this persistent fever, he was treated with aureomycin orally for nine days and became afebrile on the first day of treatment. His fever did not recur and there was marked subjective improvement.

Therapy by the oral and intramuscular routes in six patients was begun on the third, fourth, seventh, tenth, 14th and 27th days respectively, after onset of illness. Temperature returned to normal in these six patients within 25,26 , four, 25 , five and 18 days, respectively. Four of these patients were severely ill and large amounts of the antibiotic were given; because of severe nausea three of these individuals tolerated the drug poorly. The seventh patient in this group had run a prolonged convalescence with low-grade fever following an acute attack of $Q$ fever nine weeks before; he became afebrile on the first day of treatment and remained afebrile.

One severely ill individual was treated by the combined oral and intravenous routes. $\mathrm{He}$ received a total of $2,100 \mathrm{mg}$. parenterally and 40.0 grams orally in two courses over a period of eight days. Treatment was begun on the 16th day of illness; 29 days later the patient remained febrile but improved, and the drug appeared to have had little effect on the course of the illness.

\section{Primary Atypical Pneumonia}

In the present investigation there were 16 patients treated with aureomycin whose clinical course and physical findings were such as to warrant a diagnosis of primary atypical pneumonia (28). These patients all had unequivocal roentgenologic evidence of pneumonia; a total white blood count of below 15,000 and temperature re- 
cordings of at least $102^{\circ} \mathrm{F}$., before therapy was instituted. Several of these patients were exceptionally ill and none of those treated with penicillin had shown any improvement. Of the 11 patients from whom serum specimens were obtained at appropriate times there were seven who showed a cold agglutinin titer of 1:40 or more. Each of the two most severely ill patients had titers of $1: 640$, the remainder falling between $1: 40$ and $1: 60$.

In 14 of the 16 patients there was prompt initial symptomatic improvement and return of temperature to within normal range within 72 hours following institution of aureomycin. There were several whose response was extraordinarily rapid. The remaining two patients while showing clinical improvement remained febrile for somewhat longer periods. One patient appeared to relapse after drug had been stopped following good initial response. One of the patients who had shown a good initial response appeared to relapse after the drug had been stopped, with return of lowgrade fever and an increase in the X-ray evidence of pneumonia. This sequence of events has been observed to occur in other patients treated with aureomycin in another study (29). There follows a detailed case history of a patient with primary atypical pneumonia in whom treatment was carried out by the intravenous route alone. This case is summarized in Figure 4.

Case 5. T. B., white, male, age 17 (UCH 163710). This patient entered the University of California Hospital on February 25, 1949, complaining of a dry, hacking cough of two weeks' duration. On the day preceding hospital admission he had developed substernal pain and fever, and cough had become productive of a moderate amount of yellowish sputum. He had had asthma as a child but had suffered no attacks during the past 10 years.

On examination the temperature was $38.5^{\circ} \mathrm{C}$., pulse 100 per minute, and respiration 20 per minute. The patient did not appear acutely ill but coughed frequently.

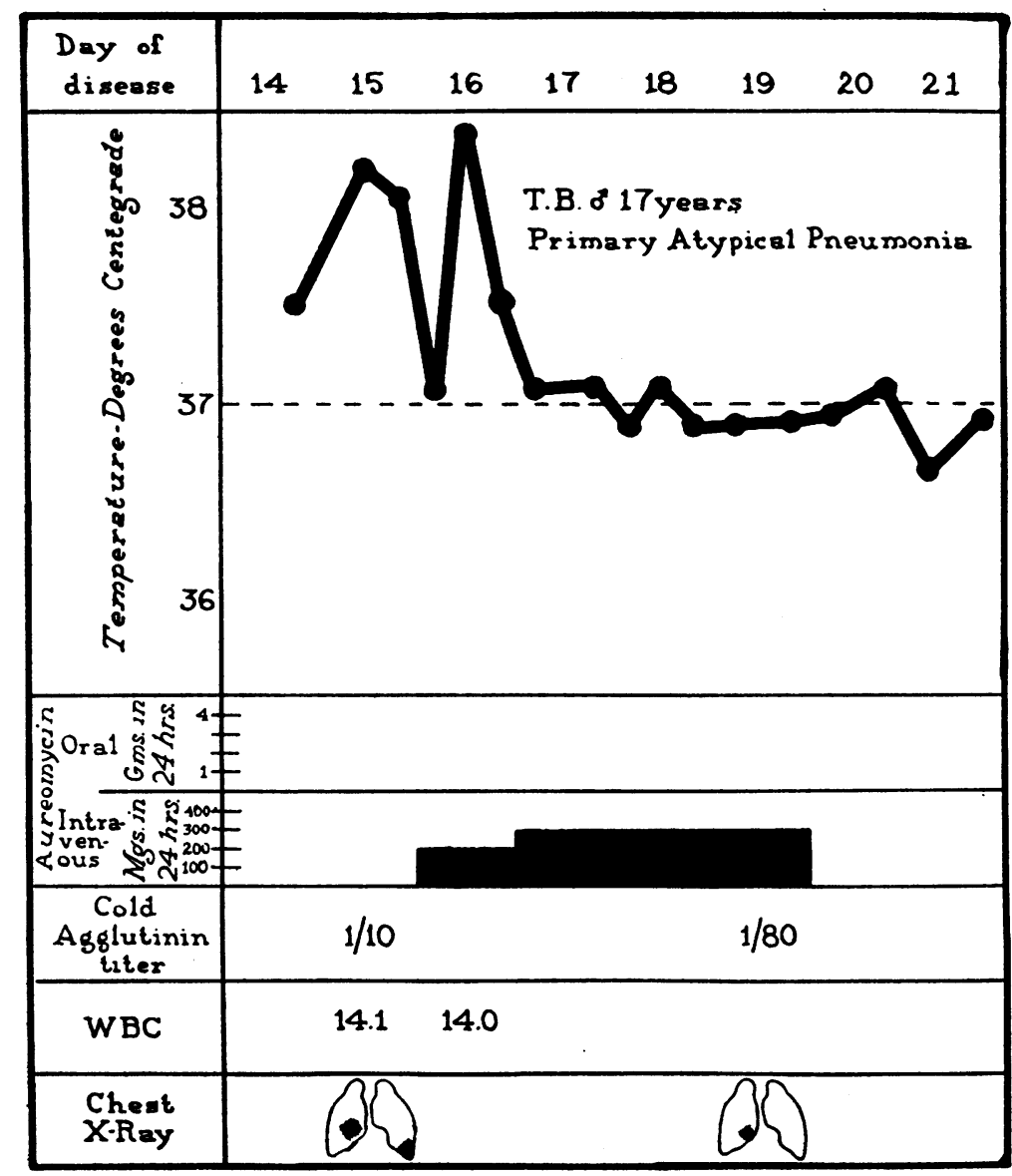

Fig. 4 


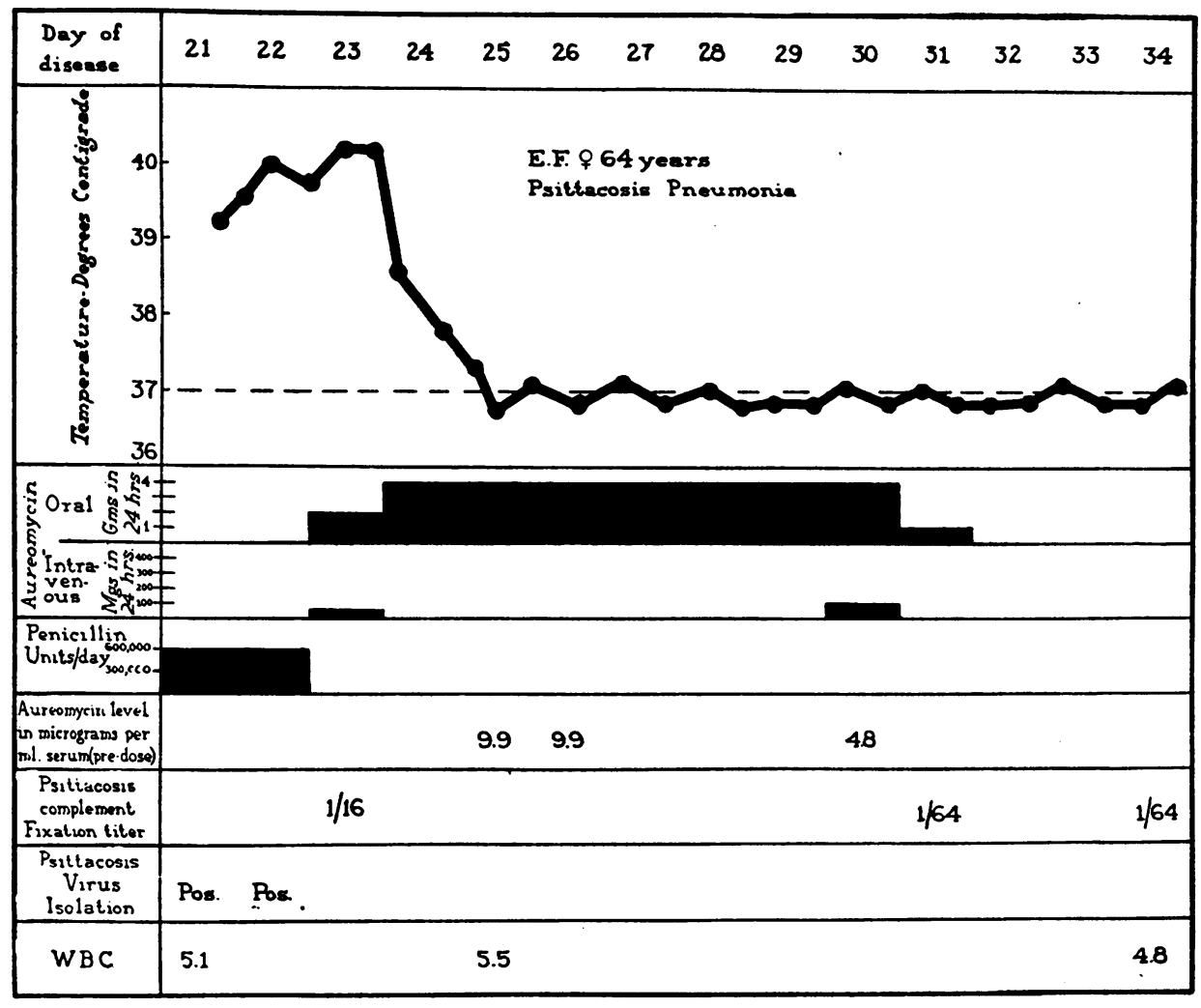

Fig. 5

Squeaking fine and coarse rales were heard in both lung bases posteriorly. Physical examination was otherwise within normal limits.

Urinalysis was normal. Complete blood count showed: Hemoglobin 16.5 grams per cent; red blood cells 5,100,000 per cubic mm.; white blood cells 14,150 per cubic mm.; neutrophiles 77 per cent; lymphocytes 12 per cent; monocytes 11 per cent. Corrected sedimentation rate (Wintrobe) was $17 \mathrm{~mm}$. per hour. Throat culture was negative for pathogens. Chest X-ray revealed pneumonitis in both right and left lower lobes. Cold agglutinins were present in a dilution of $1: 20$ at the time of entry. This titer rose to $1: 80$ five days later.

$100 \mathrm{mg}$. of aureomycin in leucine diluent was administered intravenously every eight hours from February 26 to March 1. The patient became afebrile and improved symptomatically within 24 hours. The rales disappeared from the chest by February 27 . A chest film on March 2 revealed almost complete clearing of the previously noted pneumonitis.

\section{Psittacosis}

Trial of aureomycin in psittacosis was of particular interest because laboratory investigation suggested that this drug was highly effective in vivo (7). Penicillin has been found to be an ef- fective therapeutic agent in a small number of reported cases as reviewed by Goggio (30). A larger number of cases with favorable therapeutic response is unreported (31).

Three patients with a diagnosis of psittacosis have been treated with aureomycin. In one the diagnosis was established by isolation of the virus and demonstration of an increase in complementfixing antibody titer. The second diagnosis was based on the presence in the convalescent serum of complement-fixing antibody in a titer of $1: 256$. In the third, the diagnosis was based on a history of contact with infected birds, typical clinical course, and the fact that the patient's wife, who was ill at the same time, was shown to have a complement-fixing titer of $1: 64$. This patient himself did not develop complement-fixing antibody in significant titer. The diagnosis in the last two patients must be considered incompletely established. All three of these patients appeared to respond to aureomycin therapy.

The first case, E. F., is presented in detail below (Figure 5). 
Case 6. E. F., white, female, age 64 ( $\mathrm{SFH} 25740$ ). The patient entered the San Francisco Hospital December 12, 1948, giving a history of anorexia of four weeks' duration followed by generalized aching and malaise for the three weeks preceding hospital entry. Two weeks before admission she developed a severe productive cough and high fever accompanied by sweats. On October 26, 1948, she had been given a parakeet which died one week later. No other members of the household had been ill, but two cases of psittacosis had recently been diagnosed as arising from parakeets obtained from the same source.

Past history was irrelevent except that the patient had had chronic productive cough for 40 years.

On examination the temperature was $39.5^{\circ} \mathrm{C}$., pulse 86 per minute, and respiration 32 per minute. The patient appeared severely ill and drowsy. Dullness, diminished breath and voice sounds and fine and medium rales were noted over both lower lung lobes. Physical examination was otherwise essentially negative.

Urinalysis was normal. The blood count showed: Hemoglobin 11.2 grams per cent; red blood cells $3,210,000$ per cubic mm.; white blood cells 5,150 per cubic mm.; polymorphonuclear leukocytes 60 per cent; eosinophiles 2 per cent; lymphocytes 38 per cent. Corrected sedimentation rate (Wintrobe) $42 \mathrm{~mm}$. per hour. Mazzini test was negative. Blood culture was sterile. Throat culture revealed no pathogens. Stool culture was negative. Sputum was repeatedly negative for tubercle bacilli. Cold agglutinins were not demonstrated on December 16 and December 22. Complement fixation reaction for psittacosis was positive in a titer of $1: 12$ on December 14 and rose to $1: 64$ within a week. Psittacosis virus was recovered from the sputum by inoculation of cotton rats and mice. Agglutinations for typhoid, paratyphoid, and brucellosis were negative December 13 and 14 . Complement-fixation for $Q$ fever was negative. Chest $X$-ray revealed patchy accentuation of pulmonary markings radiating from both hila which was believed compatible with bronchopneumonia.

The patient received 300,000 units of penicillin procaine complex twice daily on December 13 and 14 at which time virus was still demonstrable in the sputum and fever unabated. On the evening of December 13 the patient was started on aureomycin 1 gram by mouth every six hours which she received until December 22.

$50 \mathrm{mg}$. was administered intravenously at the time of the first oral dose. The patient became afebrile within 24 hours and remained so subsequently. Symptomatic improvement was prompt although the patient suffered from nausea and occasional vomiting considered due to aureomycin which was severe enough on one occasion to necessitate an intravenous dose of $100 \mathrm{mg}$. On December 17 the chest was negative to physical examination. Chest film taken on December 18 showed marked diminution of the inflammatory reaction previously seen. The patient was discharged as well on December 27, 1948.

The second patient, a male aged 38 years, was treated with aureomycin on the 12th day of the disease and, following failure of response to repository penicillin, showed prompt symptomatic improvement. The temperature, which had been as high as $105^{\circ} \mathrm{F}$. before therapy, dropped rapidly but a low-grade fever persisted for eight days.

The third patient, a male aged 47 years, who was admitted to the hospital on the fifth day of the disease, was treated with repository penicillin in doses of 300,000 units twice a day for five days. At the time penicillin was stopped the patient's temperature was $102^{\circ} \mathrm{F}$. During the following three days, the patient's temperature fell gradually to normal but rose again to a level of $104^{\circ} \mathrm{F}$. on the 15 th day of the disease. Following institution of aureomycin therapy at this point, the temperature fell to below $100^{\circ} \mathrm{F}$. within 48 hours and, with the exception of a single spike, remained below $100^{\circ} \mathrm{F}$. thereafter with occasional temperature elevations to $99.4^{\circ} \mathrm{F}$. until the $23 \mathrm{rd}$ day of illness. Within two days after starting the drug, marked symptomatic improvement was noted. These cases illustrate relatively poor response to repository penicillin and subsequent good response to aureomycin.

\section{Miscellaneous Diseases}

A small group of patients suffering from bacterial pneumonias and pneumonia of unknown etiology was treated with aureomycin. In addition, one patient with proven primary coccidioidal pneumonia received aureomycin in full dosage for five days without demonstrable effect. Of two patients with pneumococcal pneumonia, one became afebrile within 12 hours; the other continued to have lowgrade fever after an initial critical response until the introduction of penicillin treatment. One child who had chronic cystic fibrosis of the pancreas on which staphylococcal pneumonitis was superimposed evidenced slight temporary depression of fever followed by relapse. In five patients with pneumonia of unproven etiology response to aureomycin varied from none to excellent. One patient died of septicemia and pneumonia due to Pseudomonas aeruginosa in spite of exceedingly high serum levels of aureomycin during one and one-half day's treatment.

Two patients with generalized peritonitis of appendiceal origin, but whose infecting organisms. were unknown, responded satisfactorily to aureo- 
mycin after becoming worse while under penicillin therapy. One patient with a peritoneal abscess, from which $E$. coli was cultivated, recovered promptly but the beneficial result was probably not attributable entirely to aureomycin, since colpotomy was done. One chronic fecal fistula following appendectomy did not close during two weeks treatment with aureomycin.

Dramatic healing was observed in an infant suffering from chronic pyodermia due to a penicillinresistant staphylococcus. One of three patients with pemphigus appeared to go into remission while being treated with aureomycin, but new lesions developed 12 days after treatment was stopped. Another patient with pemphigus was treated during a period of apparent spontaneous improvement, making the result difficult to evaluate. A third patient did not improve. One patient who had herpes zoster ophthalmicus healed dramatically within one week of the beginning of aureomycin treatment. No apparent beneficial effect was observed in one patient who developed varicella while receiving aureomycin. Another patient with chickenpox developed no new lesions after aureomycin was begun on the second day of eruption. One patient who had erysipelas responded satisfactorily to aureomycin. The fever and bacteremia in two patients suffering from subacute bacterial endocarditis due to penicillinresistant Streptococcus fecalis disappeared during treatment with aureomycin but recurred one and seven days respectively after the termination of long courses of therapy. In one of these patients the blood culture became sterile only after serum concentrations of aureomycin of 10 to $20 \mu \mathrm{g}$. were attained.

Four patients with primary chancroidal ulcers of the penis and inguinal adenitis responded promptly to aureomycin therapy by rapid healing of the ulcers and subsidence of adenitis. One patient with inguinal adenitis due to lymphopathia venereum also appeared to respond satisfactorily.

No definite therapeutic effect was observed in three patients suffering from infectious mononucleosis. One patient with stomatitis, balanourethritis, conjunctivitis, and arthritis did not manifest therapeutic effect from aureomycin. No beneficial effect was observed from the treatment of Hodgkin's disease, acute leukemia, or carcinoma of the parotid gland.

\section{DISCUSSION}

Available data indicate that aureomycin will assume an important place in the physician's armamentarium. Its role as the preferred agent in the treatment of primary atypical pneumonia, psittacosis, leptospirosis, and infections of the urinary tract by Streptococcus fecalis seems likely to be established. The rarity of development of drugresistant organisms would suggest its curative or suppressive value in the treatment of urinary tract infection due to susceptible organisms either in the presence or absence of obstructive lesions. Preliminary data would also indicate the promise of aureomycin in chancroid and lymphopathia venereum infections. Although acute brucellosis appears to be generally amenable to treatment with this antibiotic, its value in chronic brucellosis remains to be proven. In spite of excellent results in the majority of $Q$ fever infections, treatment failures have been encountered. Results reported by others in typhus and Rocky Mountain spotted fever in small series of patients appear even more favorable $(6,10,14,16,19,22,24)$. As yet inadequately explored is the place of aureomycin in the treatment of herpes zoster, varicella and herpes simplex.

As an alternative agent to penicillin in infections due to gram-positive cocci and Neisseriae, aureomycin offers great promise, especially where penicillin resistance is encountered. Furthermore, because of its very wide spectrum of activity, aureomycin may assume a dominant role in the treatment of acute infections where the exact etiology is unknown, as in "atypical" pneumonias of all sorts. The relative value of aureomycin and streptomycin in the treatment of infections due to gramnegative organisms susceptible to both agents cannot yet be estimated, but at least aureomycin will serve as an alternative agent in this field. Comparison of aureomycin and chloromycetin in the treatment of rickettsial and certain viral and bacterial diseases must await carefully controlled studies.

In infections due to E. typhosa and the Salmonellae, aureomycin appears to be of limited usefulness. Although definite beneficial effect appears to result in some cases, frequent failures occur and cannot be entirely explained on the basis of inadequate serum concentrations. The activity of 
aureomycin against infections due to $P s$. aeruginosa and $\mathrm{Pr}$. vulgaris appears to be very limited, even in the urinary tract where very high concentrations of the antibiotic are usually attainable (26).

Unlike penicillin and streptomycin, but somewhat reminiscent of the sulfonamide drugs, aureomycin often appears to exert a greater or lesser suppressive effect on the infecting agent without producing its complete destruction. Aureomycin may interfere with the development of complementfixing antibodies in psittacosis and cold agglutinins in primary atypical pneumonia (29).

With the exception of nausea and vomiting, aureomycin compares favorably with penicillin in lack of significant toxic effects in relation to antiinfective activity. Even this side effect may be avoided by use of the intravenous route of administration. Furthermore, approximately one-tenth as much drug need be given intravenously as by mouth. Reduction of the oral dose or further purification of the antibiotic may also obviate gastrointestinal symptoms.

\section{SUMMARY AND CONCLUSIONS}

1. Aureomycin was used in the treatment of $\mathbf{1 1 6}$ patients with infections due to a variety of bacterial, rickettsial and viral agents.

2. The only significant toxic symptom encountered frequently was nausea and vomiting.

3. The intravenous route of administration, used in 68 individuals, proved to be an effective method of therapy, both when used to supplement oral medication to produce high serum concentrations of aureomycin, or to replace the oral route in the control of nausea and vomiting.

4. Aureomycin appeared to exert beneficial effect in acute brucellosis, leptospirosis, $Q$ fever, primary atypical pneumonia, psittacosis, chancroid, lymphopathia venereum, generalized peritonitis, and many infections of the urinary tract.

5. Beneficial effects from aureomycin therapy appeared to be limited or absent in typhoid, Salmonella, Shigella infections, coccidioidal pneumonia, infectious mononucleosis, varicella and subacute bacterial endocarditis due to Streptococcus fecalis.

\section{BIBLIOGRAPHY}

1. Duggar, B. M., Aureomycin : a product of the continuing search for new antibiotics. Ann. N. Y. Acad. Sc., 1948, 51, 177.

2. Price, C. W., Randall, W. D., and Welch, H., Bacteriological studies of aureomycin. Ibid., 1948, 51, 211.

3. Paine, T. F., Jr., Collins, H. S., and Finland, M., Laboratory studies with aureomycin. Ibid., 1948, $51,228$.

4. Collins, H. S., Paine, T. F., Jr., and Finland, M., Clinical studies with aureomycin. Ibid., 1948, 51, 231.

5. Little, P. A., Use of aureomycin on some experimental infections in animals. Ibid., 1948, 51, 246.

6. Bryer, M. S., Schoenbach, E. B., Bliss, E. A., and Chandler, C. A., Treatment of experimental infections with aureomycin. Ibid., 1948, 51, 254.

7. Wong, S. C., and Cox, H. R., Action of aureomycin against experimental rickettsial and viral infections. Ibid., 1948, 51, 290.

8. Anigstein, L., Whitney, D. M., and Beninson, J., Aureomycin-a new antibiotic with antirickettsial properties; its effect on experimental spotted fever and epidemic typhus. Ibid., 1948, 51, 306.

9. Harned, B. K., Cunningham, R. W., Clark, M. C., Cosgrove, R., Hine, C. H., McCauley, W. J., Stokey, E., Vessey, R. E., Yuda, N. N., and Subba Row, Y., The pharmacology of dyomycin. Ibid., 1948, 51, 182.

10. Dowling, H. F., Lepper, M. H., Sweet, L. K., and Brickhouse, R. L., Studies on serum concentrations in humans and preliminary observations in the treatment of human infections with aureomycin. Ibid., 1948, 51, 241.

11. Braley, A. E., and Sanders, M., Aureomycin in ocular infections. Ibid., 1948, 51, 280.

12. Wright, L. T., Sanders, M., Logan, M. A., Prigot, A., and Hill, L. M., The treatment of lymphogranuloma venereum and granuloma inguinale in humans with aureomycin. Ibid., 1948, 51, 318.

13. Lennette, E. H., Meiklejohn, G., and Thelen, H. M., Treatment of $Q$ fever in man with aureomycin. Ibid., 1948, 51, 331.

14. Bryer, M. S., Schoenbach, E. G., Chandler, C. A., Bliss, E. A., and Long, P. H., Aureomycin. J. A. M. A., 1948, 138, 117.

15. Wright, L. T., Sanders, M., Logan, M. A., Prigot, A., and Hill, L. M., Aureomycin; a new antibiotic with virucidal properties. J. A. M. A., 1948, 138, 408.

16. Cooke, C., Rocky Mountain spotted fever treated with aureomycin. J. A. M. A., 1948, 138, 885.

17. Finland, M., Collins, H. S., and Paine, T. F., Jr., Aureomycin: a new antibiotic. J. A. M. A., 1948, 138, 946. 
18. Spink, W. W., Braude, A. I., Castaneda, M. R., and Goytia, R. S., Aureomycin therapy in human brucellosis due to Brucella melitensis. J. A. M. A., 1948, 138, 1145.

19. Ross, S., Schoenbach, E. B., Burke, F. G., Bryer, M. S., Rice, E. C., and Washington, J. A., Aureomycin therapy of Rocky Mountain spotted fever. J. A. M. A., 1948, 138, 1213.

20. Kneeland, Y., Jr., Rose, H. M., and Gibson, C. D., Aureomycin in the treatment of primary atypical pneumonia. Am. J. Med., 1949, 6, 41.

21. Schoenbach, E. B., and Bryer, M. S., Treatment of primary atypical non-bacterial pneumonia with aureomycin. J. A. M. A., 1949, 139, 275.

22. Schoenbach, E. B., Aureomycin therapy of recrudescent epidemic typhus (Brill's disease). J. A. M. A., 1949, 139, 450.

23. Finland, M., Collins, H. S., and Wells, E. B., Aureomycin in the treatment of primary atypical pneumonia. New England J. Med., 1948, 240, 241.

24. Long, P. H., Schoenbach, E. B., Bliss, E. A., Bryer, M. S., and Chandler, C. A., The experimental and clinical use of polymyxin, chloromycetin, and aureomycin. Calif. Med., 1949, 70, 157.

25. Brainerd, H., Bruyn, H. B., Jr., Meiklejohn, G., and Scaparone, M., Assay of aureomycin in body fluids; observations on individuals receiving aureomycin. Proc. Soc. Exper. Biol. \& Med., 1949, 70, 318.

26. Brainerd, H., Bruyn, H. B., Jr., and Meiklejohn, G., The clinical pharmacology of aureomycin. (To be published.)

27. Heilman, F. R., Aureomycin in the treatment of experimental relapsing fever and leptospirosis icterohemorrhagic (Weil's disease). Proc. Staff Meetings of the Mayo Clinic, 1948, 23, 569.

28. Meiklejohn, G., Viral pneumonia. Med. Clin. N. Amer., 1947, 31, 1442.

29. Meiklejohn, G., and Schragg, R. I., A controlled evaluation of aureomycin in primary atypical pneumonia. (To be published.)

30. Goggio, A. F., Human psittacosis cured by penicillin therapy. Calif. Med., 1949, 70, 167.

31. Meiklejohn, G., and Lennette, E. H. Unpublished data. 